\title{
Folate receptor overexpression can be visualized in real time during pituitary adenoma endoscopic transsphenoidal surgery with near-infrared imaging
}

\author{
John Y. K. Lee, MD, MSCE, ${ }^{1}$ Steve S. Cho, BS, ${ }^{1,8}$ Ryan Zeh, BS, ${ }^{1}$ John T. Pierce, MS, ${ }^{1}$ \\ Maria Martinez-Lage, MD, ${ }^{2}$ Nithin D. Adappa, MD, ${ }^{3}$ James N. Palmer, MD, ${ }^{3}$ Jason G. Newman, MD, ${ }^{3}$ \\ Kim O. Learned, MD, ${ }^{4}$ Caitlin White, MD, ${ }^{5}$ Julia Kharlip, MD, ${ }^{5}$ Peter Snyder, MD, ${ }^{5}$ \\ Philip S. Low, PhD, ${ }^{6}$ Sunil Singhal, MD, ${ }^{7}$ and M. Sean Grady, MD ${ }^{1}$
}

\begin{abstract}
Departments of ${ }^{1}$ Neurosurgery, ${ }^{2}$ Pathology, ${ }^{3}$ Otorhinolaryngology, ${ }^{4}$ Radiology, ${ }^{5}$ Endocrinology, and ${ }^{7}$ Surgery, Hospital of the University of Pennsylvania, and ${ }^{8}$ Perelman School of Medicine at the University of Pennsylvania, Philadelphia, Pennsylvania; and ${ }^{6}$ Department of Biochemistry, Purdue University, West Lafayette, Indiana
\end{abstract}

\begin{abstract}
OBJECTIVE Pituitary adenomas account for approximately $10 \%$ of intracranial tumors and have an estimated prevalence of $15 \%-20 \%$ in the general US population. Resection is the primary treatment for pituitary adenomas, and the transsphenoidal approach remains the most common. The greatest challenge with pituitary adenomas is that $20 \%$ of patients develop tumor recurrence. Current approaches to reduce recurrence, such as intraoperative MRI, are costly, associated with high false-positive rates, and not recommended. Pituitary adenomas are known to overexpress folate receptor alpha (FR $\alpha$ ), and it was hypothesized that OTL38, a folate analog conjugated to a near-infrared (NIR) fluorescent dye, could provide real-time intraoperative visual contrast of the tumor versus the surrounding nonneoplastic tissues. The preliminary results of this novel clinical trial are presented.

METHODS Nineteen adult patients who presented with pituitary adenoma were enrolled. Patients were infused with OTL38 2-4 hours prior to surgery. A 4-mm endoscope with both visible and NIR light capabilities was used to visualize the pituitary adenoma and its margins in real time during surgery. The signal-to-background ratio (SBR) was recorded for each tumor and surrounding tissues at various endoscope-to-sella distances. Immunohistochemical analysis was performed to assess the FR $\alpha$ expression levels in all specimens and classify patients as having either high or low FR $\alpha$ expression.
\end{abstract}

RESULTS Data from 15 patients (4 with null cell adenomas, 1 clinically silent gonadotroph, 1 totally silent somatotroph, 5 with a corticotroph, 3 with somatotrophs, and 1 somatocorticotroph) were analyzed in this preliminary analysis. Four patients were excluded for technical considerations. Intraoperative NIR imaging delineated the main tumors in all $15 \mathrm{pa}-$ tients with an average SBR of $1.9 \pm 0.70$. The FR $\alpha$ expression level of the adenomas and endoscope-to-sella distance had statistically significant impacts on the fluorescent SBRs. Additional considerations included adenoma functional status and time from OTL38 injection. SBRs were $3.0 \pm 0.29$ for tumors with high FR $\alpha$ expression $(n=3)$ and $1.6 \pm 0.43$ for tumors with low FR $\alpha$ expression $(n=12 ; p<0.05$ ). In 3 patients with immunohistochemistry-confirmed FR overexpression (2 patients with null cell adenoma and 1 patient with clinically silent gonadotroph), intraoperative NIR imaging demonstrated perfect classification of the tumor margins with 100\% sensitivity and 100\% specificity. In addition, for these 3 patients, intraoperative residual fluorescence predicted postoperative MRI results with perfect concordance.

CONCLUSIONS Pituitary adenomas and their margins can be intraoperatively visualized with the preoperative injection of OTL38, a folate analog conjugated to NIR dye. Tumor-to-background contrast is most pronounced in adenomas that overexpress FR $\alpha$. Intraoperative SBR at the appropriate endoscope-to-sella distance can predict adenoma FR $\alpha$ expression status in real time. This work suggests that for adenomas with high FR $\alpha$ expression, it may be possible to identify margins and to predict postoperative MRI findings.

https://thejns.org/doi/abs/10.3171/2017.2.JNS163191

KEY WORDS pituitary surgery; fluorescence; folate receptor; visualization

ABBREVIATIONS FR $\alpha$ = folate receptor alpha; GTR = gross-total resection; ICG = indocyanine green; iMRI = intraoperative MRI; MOCR = medial opticocarotid recess; $\mathrm{NF}=$ nonfunctional; $\mathrm{NIR}=$ near infrared; $\mathrm{SBR}=$ signal-to-background ratio.

SUBMITTED December 20, 2016. ACCEPTED February 15, 2017.

INCLUDE WHEN CITING Published online August 25, 2017; DOI: 10.3171/2017.2.JNS163191. 
$\mathrm{P}$ ITUITARY adenomas have an estimated prevalence of $15 \%-20 \%$ in the US, and they account for approximately $10 \%$ of intracranial tumors..$^{10}$ Although they are predominantly benign, pituitary adenomas can still cause significant disability from compression of the adjacent neural structures and hypersecretory syndromes.

While prolactinomas and some somatotroph adenomas can be medically managed with cabergoline and octreotide, respectively, surgical management remains the primary treatment for nonfunctional (NF) adenomas and other functional adenomas. ${ }^{13,21}$ Currently, the endoscopic transsphenoidal approach is the most common surgical approach for resecting pituitary adenomas. The extent of resection is based on the surgeon's visual and tactile impression of the tissue. Achieving complete resection can be difficult, and the tumor recurrence rate can be as high as $20 \%$ after surgery. ${ }^{24,34}$ Some surgeons have resorted to implementing MRI scanners in the operating room to maximize extent of resection, but this remains expensive and limited in availability. ${ }^{11}$ In addition, intraoperative MRI has been shown to result in a high false-positive rate and is not currently recommended. ${ }^{16}$ This study proposes a novel optical contrast technique that takes advantage of the pituitary adenoma's overexpression of folate receptors.

Folate receptor alpha (FR $\alpha)$ overexpression has been reported in pituitary adenomas, especially NF adenomas, which overexpress FR $\alpha$ more than 20 times above the level of the normal pituitary gland and surrounding intracranial structures. ${ }^{7,8,18}$ This makes FR $\alpha$ an attractive target for specific labeling of pituitary adenoma with a fluorescent dye that can be visualized intraoperatively. ${ }^{32}$ OTL38 (On Target Laboratories) is a folic acid analog conjugated to an analog of indocyanine green (ICG), a near-infrared (NIR) fluorescent dye. This conjugated dye binds folate receptors. Fluorescence in the NIR range has advantages over visible light by virtue of its superior tissue penetration and lack of autofluorescence in normal tissues..$^{25} \mathrm{We}$ hypothesized that OTL38 would selectively bind to the folate receptors on pituitary adenomas that overexpress FR $\alpha$ and allow intraoperative visualization of neoplastic tissue.

\section{Methods Study Design}

This prospective cohort study was approved by the University of Pennsylvania Institutional Review Board, and all patients gave informed consent. Adult patients over the age of 18 years who presented with a pituitary tumor were eligible for this study. Pregnancy and history of allergy to Benadryl (Johnson \& Johnson) or OTL38 were the main exclusion criteria. All patients underwent preoperative MRI of the brain and sella with and without gadolinium contrast (Table 1). Patients were informed that enrollment in the study would not substantially change the scope of surgery, as resection would proceed with conventional techniques. Margin biopsies, however, would be obtained to study the value of intraoperative NIR imaging.

\section{OTL38 Administration}

Patients who were enrolled in this study were instructed to stop taking any folate supplements, including multivita- mins, 48 hours prior to surgery to reduce interactions with OTL38. Two to 4 hours prior to surgery, patients were injected with $25 \mathrm{mg}$ Benadryl to minimize allergic reactions, and $0.025 \mathrm{mg} / \mathrm{kg}$ OTL38 was infused over the course of 1 hour. Patients were monitored for adverse reactions during and 30 minutes after infusion, and then they were checked in for surgery.

\section{Surgical Approach}

A uninostril or binostril endoscopic endonasal approach was performed in all patients. The endonasal approach was performed by otorhinolaryngologists, primarily using an endoscopic camera and endoscope system (Storz). The choice of the uninostril or binostril approach was made based on patient anatomy. ${ }^{6,29}$ A standard transnasal approach was employed by opening both sphenoid sinuses, removing the sphenoid rostrum, and resecting the sphenoid intersinus septum. The mucosa of the sella was removed in an atraumatic fashion to keep the surgical field dry. After exposing the sella face and sella floor, the sella was opened using standard techniques, and the dura was kept intact as much as possible to visualize NIR signal through the dura. Once the dura was opened, the NIR camera system was used to visualize fluorescence within the tumor. Tumor resection was performed using standard Storz endoscopic equipment, and, on completion, the NIR camera system was brought back in to inspect the resection margins. On satisfactory completion of the surgery, closure was performed jointly by otorhinolaryngology and neurosurgery personnel depending on the need for CSF leak repair. Abdominal fat was harvested only in select cases; in other instances, either a free mucosal graft or nasoseptal flap was used.

\section{NIR System}

In all cases, the NIR signal was visualized using the Visionsense Iridium camera system (Visionsense). This system is FDA approved for perfusion imaging in plastic and reconstructive surgery (for example, to assess tissue flap vascularity). The Visionsense Iridium camera system was coupled to a dedicated 4-mm outer-diameter endoscope (Fig. 1). The excitation source is a laser tuned to the NIR range $(785 \mathrm{~nm})$, and the sensor was filtered for emissions in the 800- to 835-nm range. The endoscope consists of a 4-mm outer-diameter scope, which features a dual optical path design, allowing the separate and independent use of white light and NIR light. Having separate paths for visible light and NIR images allows very faint fluorescence images to be acquired in the presence of strong white light. Image processing was performed in real time and displayed at 1080-pixel video resolution, with recording at 720 pixels.

DSouza et al. recently compared the Visionsense Iridium system with 5 other commercially available fluorescent visualization systems, including those manufactured by PerkinElmer (Solaris), Quest, Novadaq, and others. ${ }^{5}$ They concluded that the Visionsense Iridium system demonstrates the highest sensitivity for NIR fluorescent dye: its sensitivity is in the picomolar range for IRDye 800 (LI-COR Biosciences), which has excitation and emission 


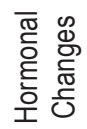

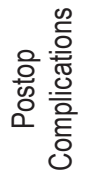

흐음

产 을 틀

崖

응 응

웅

高

혹

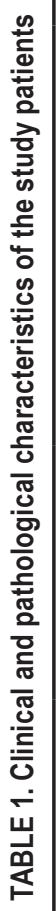

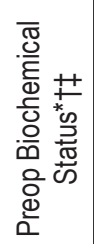

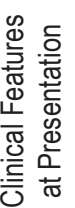

올 을

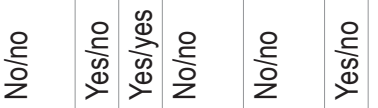

옹 옹 응

要焉希

忍

$\dot{3}$

ما

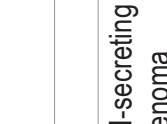

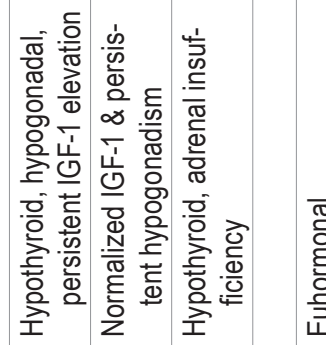

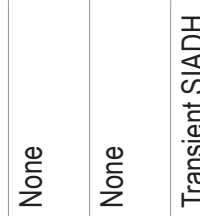

요 응

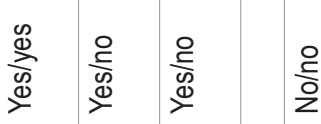

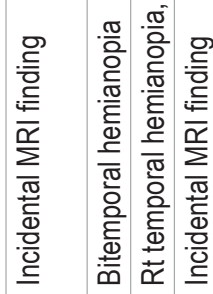

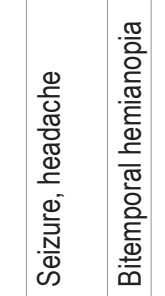

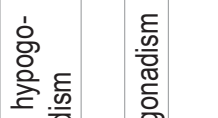

를

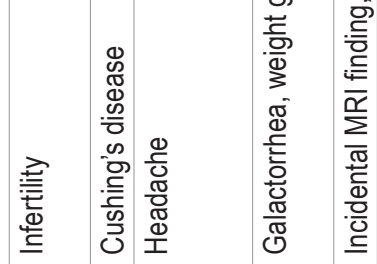

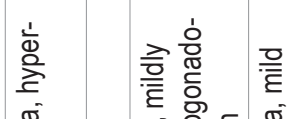

.

惫

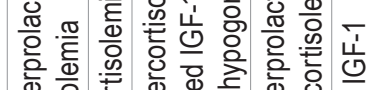

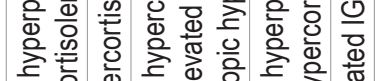

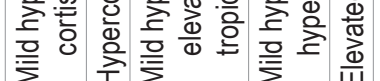

$\sum$ 工

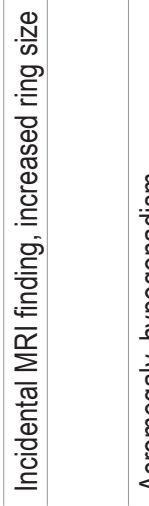

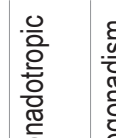

苋

旁

荘 䨌

항 훙 $\frac{0}{0}$

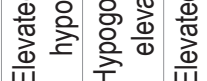

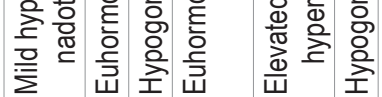

焉 焉

至焉

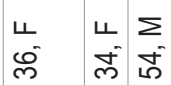

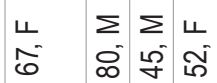

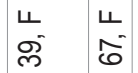

ㄴ.

西

\&

需要

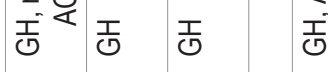

$\sum \Sigma u \quad \Sigma$

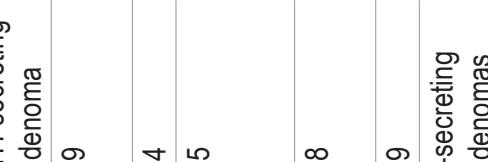

을 을

8

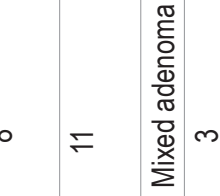

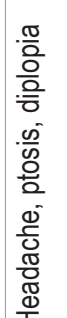

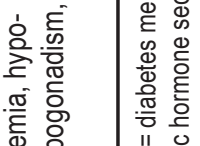

毫 只士

$\sum^{\circ}$ 喜

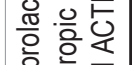

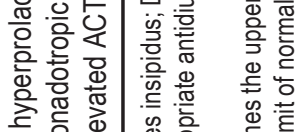

흘

这

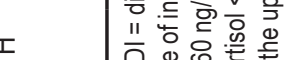

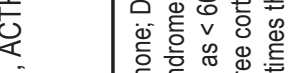



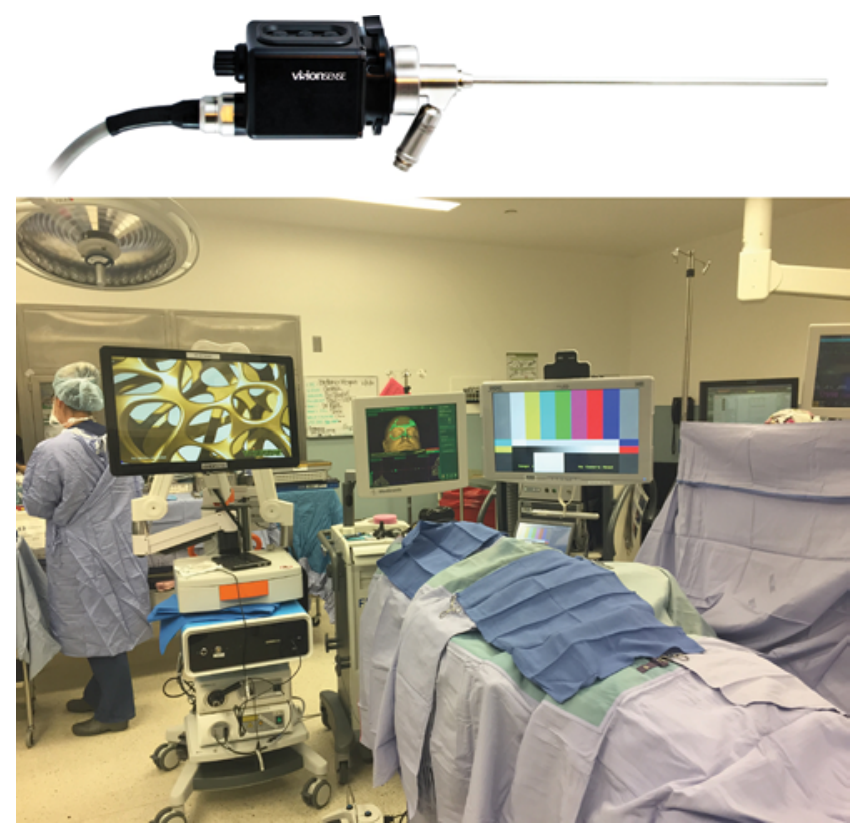

FIG. 1. Visionsense equipment setup for NIR imaging. Upper: The excitation laser for NIR imaging is attached to a 4-mm endoscope. Copyright Visionsense. Published with permission. Lower: Images are displayed on the leftmost screen. Figure is available in color online only.

characteristics that are similar to OTL38 and ICG. In addition to high sensitivity, the Visionsense system features a "smart image processing algorithm to produce a wide dynamic range," which allows for better comparisons of high and low signal-to-background ratios (SBRs). ${ }^{5}$

\section{Study Procedure}

On encountering the tumor, the Visionsense Iridium 4-mm endoscope was used to simultaneously view white light and NIR images (Fig. 2). These 2 images were superimposed on the video output in real time to allow intraoperative analysis of the NIR signal. The NIR signal through the dura was recorded, as was the NIR signal through the pituitary adenoma after the dura was opened. After pituitary exposure, specimens were obtained of the mass and coded by the attending surgeon (J.Y.K.L. or M.S.G.) as consistent with the tumor based on the surgeon's impression under white light (yes vs no) and NIR fluorescence (yes vs no) and then sent to the pathology laboratory for histopathological diagnosis. Surgery then proceeded in the standard-of-care manner without the use of NIR fluorescence.

After the tumor had been resected and the attending neurosurgeon was satisfied that complete resection had been achieved based on white light visualization, NIR imaging was used to identify areas of residual disease (Fig. $2 \mathrm{E}$ and $\mathrm{F}$ ). Areas were biopsied at the discretion of the senior surgeon (J.Y.K.L. or M.S.G.), and specimens were coded and sent to the pathology laboratory.

Patients were admitted to the intensive care unit following surgery, and no adverse outcomes were reported. Postoperative MRI was performed on postoperative Day 1 , and the patients were seen approximately 2 and 4 weeks after resection.
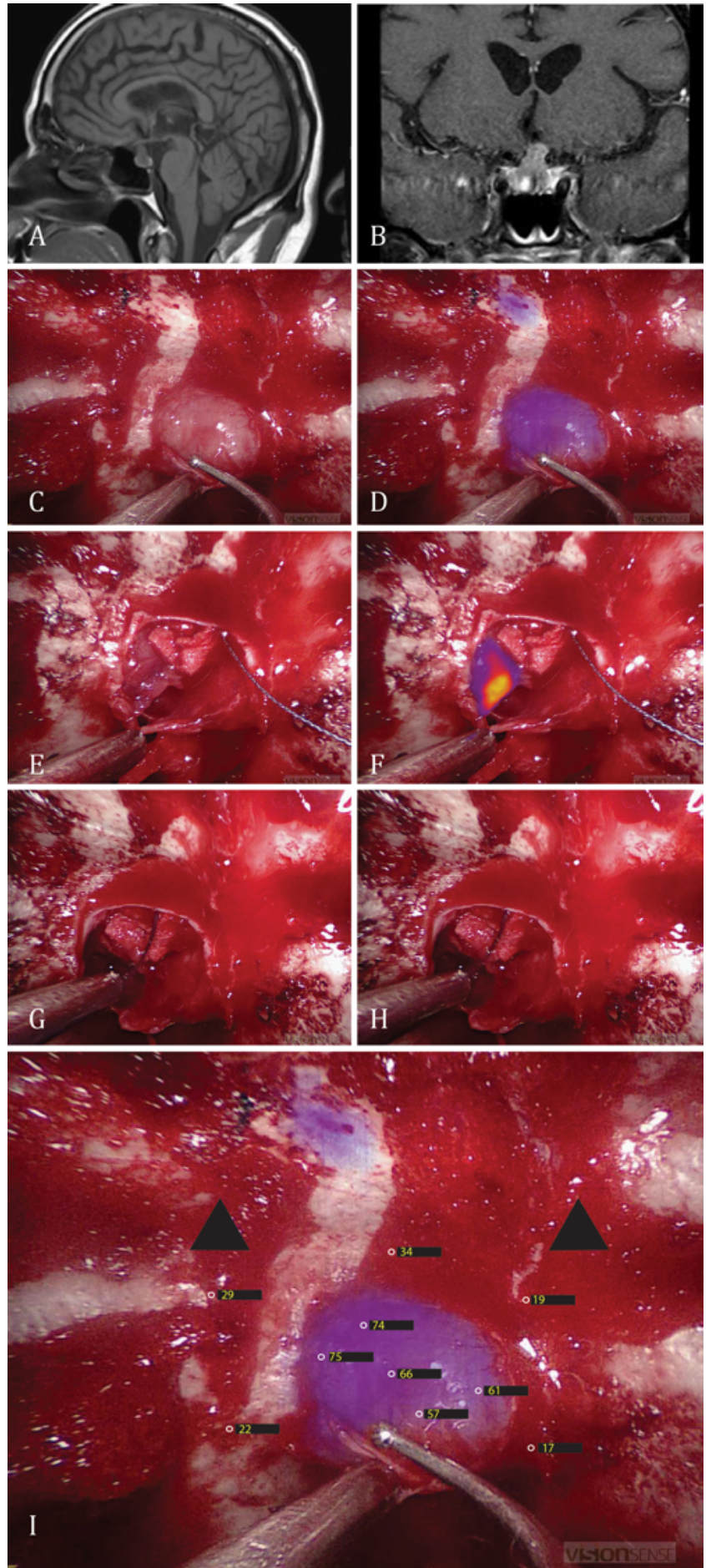

FIG. 2. Case 7. This patient had an NF adenoma, high FR $\alpha$ expression on final pathological analysis, and intraoperative NIR fluorescence. A and B: Preoperative sagittal (A) and coronal (B) MR images without contrast showing a 17-mm mass in the sella. C and D: Intraoperative endoscopic imaging with the dura open shown with white light only (C) and the NIR signal superimposed on white light (D). The MOCRs can be seen clearly and are used as a measure of distance from the endoscope to the target. FIG. 2. (continued) $\rightarrow$ 
FIG. 2. E and F: Intraoperative endoscopic image of the sella after resection of the gross tumor. The residual tumor was identified on the right, both with white light only $(E)$ and the NIR signal superimposed on the white light $(F)$. This fluorescent specimen was confirmed on the final pathological analysis to be consistent with pituitary adenoma. $\mathbf{G}$ and $\mathbf{H}$ : Intraoperative endoscopic image of sella contents after resection of the residual neoplasm with white light only $(G)$ and NIR superimposed on white light $(H)$. No obvious fluorescence is identified. I: Example of SBR and MOCR calculation. Five points are chosen in the gross tumor itself, with the Visionsense camera calculating NIR signal for the points $(75+$ $74+66+61+57) / 5=67 \pm 7.9$. Five points are chosen in the surrounding bone close to the tumor but outside of the obvious specimen $(22+$ $29+34+19+17) / 5=24 \pm 7.1$. The SBR is thus $67 / 24=2.8$. The black triangles denote the locations of the MOCRs, spanning roughly $50 \%$ of the field, that were used to approximate the endoscope distance.

\section{Immunohistochemistry for FR $\alpha$}

The specimens obtained from each patient were chemically fixed, embedded in paraffin blocks, and cut to 5- $\mu \mathrm{m}-$ thick sections. These permanent sections were stained with $\mathrm{H} \& \mathrm{E}$. Furthermore, immunohistochemical analysis against FR $\alpha$ was performed using murine monoclonal antibodies against the folate receptor (1:20 dilution of NCLL-FR $\alpha$, Leica Biosystems). To quantify FR $\alpha$ expression in each sample, $\mathrm{H}$-scores were calculated by a single, blinded neuropathologist (M.M.L.) using a positive control as the standard, by summing the percentages of adenoma cells that stained strongly (3+) multiplied by 3 , the percentage of adenoma cells that stained moderately (2+) multiplied by 2 , and the percentage of adenoma cells that stained weakly (1+) multiplied by 1 (Fig. 3 and Table 2). ${ }^{4,28}$ The $\mathrm{H}$-score ranges from 0 to 300 , with 300 implying strong staining in all cells.

\section{NIR Image Analysis of SBR and Laser Distance}

The data from 15 patients were analyzed using Visionsense software (VSPlayer v1.8.05.01; Fig. 2I). Between 3 and 5 region of interest points were placed on the adenoma, and then an additional 3-5 points of interest were placed on the surrounding normal tissue (such as the bone of the tuberculum sella or carotid prominences) to determine the signal-to-background ratio (SBR). Because the intravenous administration of OTL38 causes normal mucosa and skin to fluoresce when the laser source is sufficiently close, fluorescence in the mucosa that was more proximal to the laser than the pituitary mass was disregarded. In general, the surgeon removed the mucosa from the sella and surrounding sella as part of the normal surgical procedure.

Because the Visionsense endoscope does not have the capacity to measure the distance from the laser source to the fluorescent object, a substitute measurement for estimating this distance was developed. The medial opticocarotid recess (MOCR) provides a useful landmark in the endoscopic approach to the sella..$^{15,17,38}$ The distance between the 2 MOCRs as a fraction of the overall field size gives a rough estimate of the distance of the laser source to the fluorescent tissue (Fig. 2I).

\section{Data Analysis}

Stata (version 10, StataCorp) was used to compute the
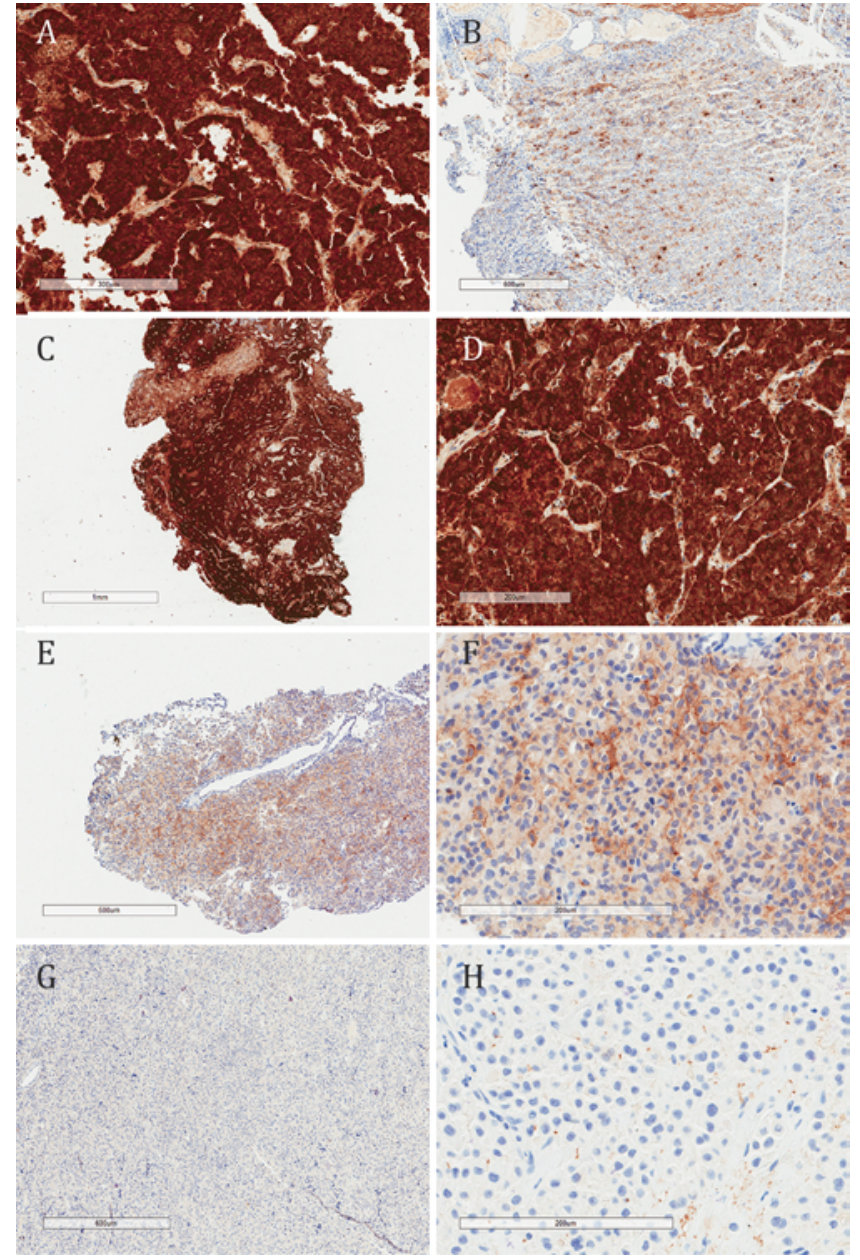

FIG. 3. Immunohistochemical examination demonstrating the level of $\mathrm{FR} \alpha$ expression in pituitary adenomas. A: Kidney is used as the positive control with an H-score of 300. Scale bar $=300 \mu \mathrm{m}$. B: Normal adenohypophysis with an $\mathrm{H}$-score of 130 . Scale bar $=600 \mu \mathrm{m}$. C and D: Case 12. Low-power (C) and high-power (D) views of the NF adenoma with a high $\mathrm{H}$-score (270). Scale bar $=1 \mathrm{~mm}$ and $200 \mu \mathrm{m}$, respectively. E and F: Case 2. Low-power (E) and high-power (F) views of the somatotroph adenoma with an intermediate $\mathrm{H}$-score of 100 . Scale bar $=500 \mu \mathrm{m}$ and $200 \mu \mathrm{m}$, respectively. G and H: Case 8. Low-power $(\mathrm{G})$ and high-power $(\mathrm{H})$ views of the somatotroph adenoma with a low $\mathrm{H}$-score of 5 . Scale bar $=600 \mu \mathrm{m}$ and $200 \mu \mathrm{m}$, respectively. Figure is available in color online only.

summary statistics and perform the t-tests and linear regression analysis.

\section{Results \\ Clinical Data}

A total of 19 patients were enrolled between October 2015 and May 2016. Two patients were excluded because the laser serving as the excitation light source malfunctioned during surgery. Two patients were excluded because their final pathological review did not demonstrate pituitary adenoma (craniopharyngioma and Rathke cleft cyst). One patient, who presented with a somatotroph adenoma and tuberculum sellae meningioma, is included in the data analysis, but SBR data were censored due to 
TABLE 2. Results of immunohistochemical analysis of FR $\alpha$

\begin{tabular}{|c|c|c|c|c|c|c|c|}
\hline Case No. & Pathology & $\begin{array}{l}\text { FR } \alpha \text { Staining } \\
\text { Intensity }\end{array}$ & $\begin{array}{l}\% \text { Cells } \\
\text { Stained }\end{array}$ & $\mathrm{H}$-Score & $\begin{array}{l}\text { SBR Close } \\
(\mathrm{MOCR}>0.7)\end{array}$ & $\begin{array}{c}\text { SBR Middle } \\
\text { (MOCR 0.4-0.7) }\end{array}$ & $\begin{array}{c}\text { SBR Far } \\
(\mathrm{MOCR}<0.4)\end{array}$ \\
\hline \multicolumn{8}{|c|}{ Nonsecretory adenoma } \\
\hline 7 & Null cell & $1+, 2+, 3+$ & $20,60,20$ & 200 & 2.9 & 2.8 & 2.8 \\
\hline 12 & Null cell & $2+, 3+$ & 30,70 & 270 & 3.9 & NA & 3.3 \\
\hline 16 & Null cell & $1+$ & 5 & 5 & 2 & 1.6 & 1.5 \\
\hline 2 & Somatotroph & $1+, 2+$ & 80,10 & 100 & 2.4 & 2.2 & NA \\
\hline \multicolumn{8}{|c|}{$\begin{array}{l}\text { ACTH-secreting ade- } \\
\text { noma }\end{array}$} \\
\hline 9 & Corticotroph & 0 & 0 & 0 & 2.2 & NA & NA \\
\hline 14 & Corticotroph & $1+$ & 5 & 5 & NA & 2.4 & 1.8 \\
\hline \multicolumn{8}{|c|}{ GH-secreting adenoma } \\
\hline 6 & Somatotroph & $1+$ & 5 & 5 & 2.2 & NA & 1.9 \\
\hline 8 & Somatotroph & $1+$ & 5 & 5 & 2.1 & NA & 1.1 \\
\hline $11^{*}$ & Somatotroph & 0 & 0 & 0 & NA & NA & 2.5 \\
\hline \multicolumn{8}{|l|}{ Mixed adenoma } \\
\hline 3 & Corticosomatotroph & $1+$ & 40 & 40 & 1.6 & 1.2 & 1 \\
\hline
\end{tabular}

$\mathrm{NA}=$ not applicable (images were not taken at this distance).

* Patient presented with an adenoma and tuberculum sellae meningioma.

interference with the NIR signal measurement from the meningioma.

Data from 15 patients were available for analysis. Seven patients were male, and the mean patient age was 53.2 years (range $35-80$ years). Six patients had NF adenomas (4 patients had a null cell adenoma, 1 patient had a clinically silent gonadotroph adenoma, and 1 patient had a totally silent somatotroph adenoma), 3 patients had somatotroph adenomas, 5 patients had corticotroph adenomas, and 1 patient had both corticotroph and somatotroph cells, as determined by immunohistochemical analysis (Table 1).

All patients tolerated injections of $0.025 \mathrm{mg} / \mathrm{kg}$ OTL38 administered 2 to 4 hours prior to surgery without adverse events. All patients did well after surgery with no unique complications identified. Seven of 9 patients with functional adenomas had postoperative control of hormonal hypersecretion. A surgical cure was not attained in the remaining 2 patients and further medical treatment was required (Table 1). The rate of gross-total resection (GTR) based on postoperative MRI was 73\% (Table 3). Residual tumor was identified on MRI only in patients with cavernous sinus invasion or a significant extrasellar tumor, such as a tumor in the sylvian fissure.

\section{Intraoperative NIR Fluorescence Using the Visionsense System}

All pituitary adenomas demonstrated some degree of a NIR fluorescent signal compared with background. Taken as a whole, the mean \pm SD SBR was $1.9 \pm 0.70$ for all sam- ples in all 15 patients. There was significant variability in the range of SBR (1-3.9; interquartile range 1.6-2.7). To explain this wide range in fluorescence, we performed a subgroup analyses using several variables: functional status (known preoperatively), distance from the endoscope to the pituitary gland (determined using the distance between the MOCRs as a proxy and known at time of surgery), time from injection (known at time of surgery), and FR $\alpha$ expression level (not known until after surgery was completed).

\section{FR $\alpha$ Overexpression}

Previous studies have demonstrated that NF pituitary adenomas overexpress FR $\alpha$ compared with functioning pituitary adenomas. ${ }^{8,12}$ Immunohistochemical analysis was performed on paraffin-embedded tissue sections using murine monoclonal antibodies to $\mathrm{FR} \alpha$, sections were examined by a single neuropathologist (M.M.L.), and H-scores (0-300) were determined (Fig. 3 and Table 2).

Three of the $6 \mathrm{NF}$ adenomas demonstrated significant FR $\alpha$ overexpression with H-scores of 200, 225, and 270. These tumors were categorized as "high FR $\alpha$ tumors." Among the 3 other patients with NF adenomas, 1 patient had a totally silent but growth hormone-staining adenoma. This tumor demonstrated an $\mathrm{H}$-score of 100. In comparison, normal adenohypophysis has an $\mathrm{H}$-score of 90 based on specimens that contain some small amount of normal pituitary gland tissue in the tissue block. Because 1 patient with an $\mathrm{H}$-score of 100 was not significantly above the background $\mathrm{H}$-score of the normal pituitary gland, we 
TABLE 3. Summary of preoperative MRI status and postresection MRI and fluorescence status

\begin{tabular}{|c|c|c|c|c|c|c|c|c|}
\hline \multirow[b]{2}{*}{ Case No. } & \multirow[b]{2}{*}{ Pathology } & \multirow[b]{2}{*}{$\begin{array}{c}\mathrm{FR} \alpha \\
\text { Overexpression }\end{array}$} & \multicolumn{4}{|c|}{ Preop Tumor Location } & \multicolumn{2}{|c|}{ Postop Tumor Detected } \\
\hline & & & Sella & Suprasellar & $\begin{array}{l}\text { Cavernous } \\
\text { Sinus }\end{array}$ & $\begin{array}{l}\text { Sylvian } \\
\text { Fissure }\end{array}$ & $\begin{array}{c}\text { Postop } \\
\text { Day } 1 \mathrm{MRI}\end{array}$ & $\begin{array}{c}\text { Postresection NIR } \\
\text { Fluorescence }\end{array}$ \\
\hline \multicolumn{9}{|c|}{ Nonsecretory adenoma } \\
\hline 5 & Null cell & No & Yes & Yes & No & No & None & None \\
\hline 7 & Null cell & Yes & Yes & Yes & No & No & None & None \\
\hline 12 & Null cell & Yes & Yes & Yes & Yes & No & Yes & Yes \\
\hline 16 & Null cell & No & Yes & No & No & No & None & None \\
\hline 1 & Gonadotroph & Yes & Yes & Yes & Yes & Yes & Yes & Yes \\
\hline 2 & Somatotroph & No & Yes & Yes & Yes & No & None & None \\
\hline \multicolumn{9}{|c|}{ ACTH-secreting adenoma } \\
\hline 9 & Corticotroph & No & Yes & Yes & No & No & None & None \\
\hline 14 & Corticotroph & No & Yes & No & No & No & None & None \\
\hline 15 & Corticotroph & No & Yes & No & Yes & No & None & None \\
\hline 18 & Corticotroph & No & Yes & No & No & No & None & None \\
\hline 19 & Corticotroph & No & Yes & No & No & No & None & None \\
\hline \multicolumn{9}{|c|}{ GH-secreting adenoma } \\
\hline 6 & Somatotroph & No & Yes & Yes & Yes & No & Yes & NA† \\
\hline 8 & Somatotroph & No & Yes & Yes & Yes & No & None & None \\
\hline $11^{*}$ & Somatotroph & No & Yes & No & No & No & None & None \\
\hline \multicolumn{9}{|l|}{ Mixed adenoma } \\
\hline 3 & Somatocorticotroph & No & Yes & No & Yes & No & Yes & None \\
\hline
\end{tabular}

* The patient had a tuberculum sellae meningioma.

$\dagger$ The laser excitation source failed after initial visualization of the tumor.

chose to categorize this patient as having a "low FR $\alpha$ tumor." The other $2 \mathrm{NF}$ adenomas were null cell adenomas and demonstrated virtually no FR $\alpha$ overexpression.

Among the 5 patients with corticotroph adenomas, all demonstrated low FR $\alpha$ expression, with $\mathrm{H}$-scores ranging from 0 to 10 . The 3 patients with somatotroph adenomas had $\mathrm{H}$-scores ranging from 0 to 5 , and 1 patient with somatocorticotroph adenoma had an $\mathrm{H}$-score of 40 .

Overall, only 3 patients were considered to have high FR $\alpha$ overexpression, and 12 patients were considered to have low FR $\alpha$ expression.

The NIR SBR of the patients with low H-scores was $1.6 \pm 0.43$, and the NIR SBR of the patients with high $\mathrm{H}-$ scores was $3.0 \pm 0.27$ ( $p<0.01$, t-test). Thus, the 3 patients with NF adenoma and high FR $\alpha$ overexpression (defined as $>200$ ) did show significantly higher NIR SBR compared with the other 12 patients.

\section{Functional Status}

Six of the 15 patients had NF adenomas. One patient's tumor positively stained for gonadotroph hormone on immunohistochemistry and 1 patient's tumor positively stained for somatotroph hormone, but the preoperative laboratory values were not suggestive of hormonal abnormality. Because clinical hormonal status is the primary information that would be known at the time of resection, rather than pathological hormone staining, we plotted SBR versus functional status. The NIR SBR of NF adenomas (2.4 \pm 0.81) was higher than the NIR SBR of functional adeno- mas $(1.6 \pm 0.48)(p<0.05)$. However, because mean values are sensitive to extreme values (e.g., tumors with an FR $\alpha$ H-score $>200$ ), we interpreted the data with a box plot to better evaluate the data (Fig. 4). As can be seen in Fig. 4, there is a significant overlap in the SBRs of functional and

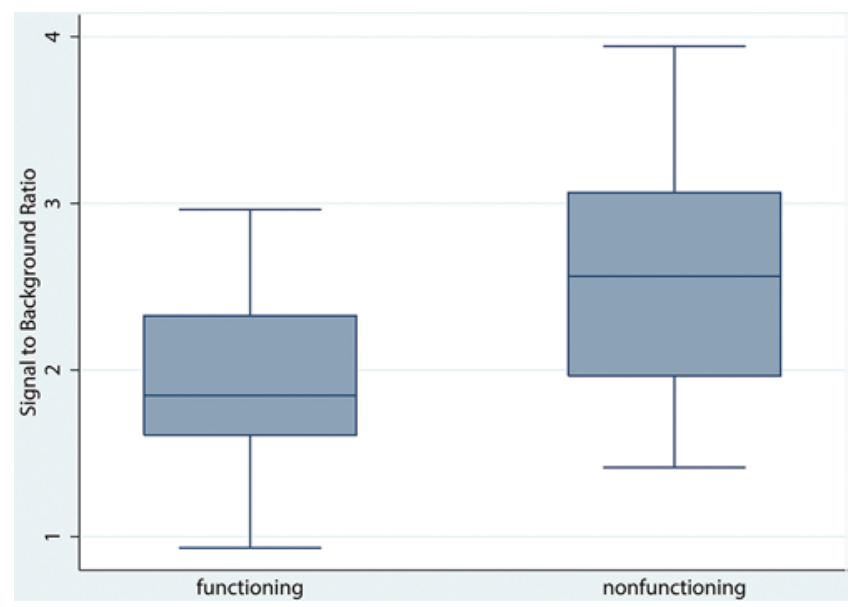

FIG. 4. Box plots showing the medians and interquartile ranges of SBR based on whether the tumor was a known functioning or NF adenoma based on preoperative clinical data. Six NF adenomas showed a mean \pm SD SBR of $2.4 \pm 0.81$ with a median of 2.5 , and 9 hormone-secreting tumors demonstrated an SBR of $1.6 \pm 0.48$ with a median of 1.7 . The difference between the 2 populations is close to statistical significance $(p=$ 0.07 ), but there is significant overlap in the interquartile range. Figure is available in color online only. 

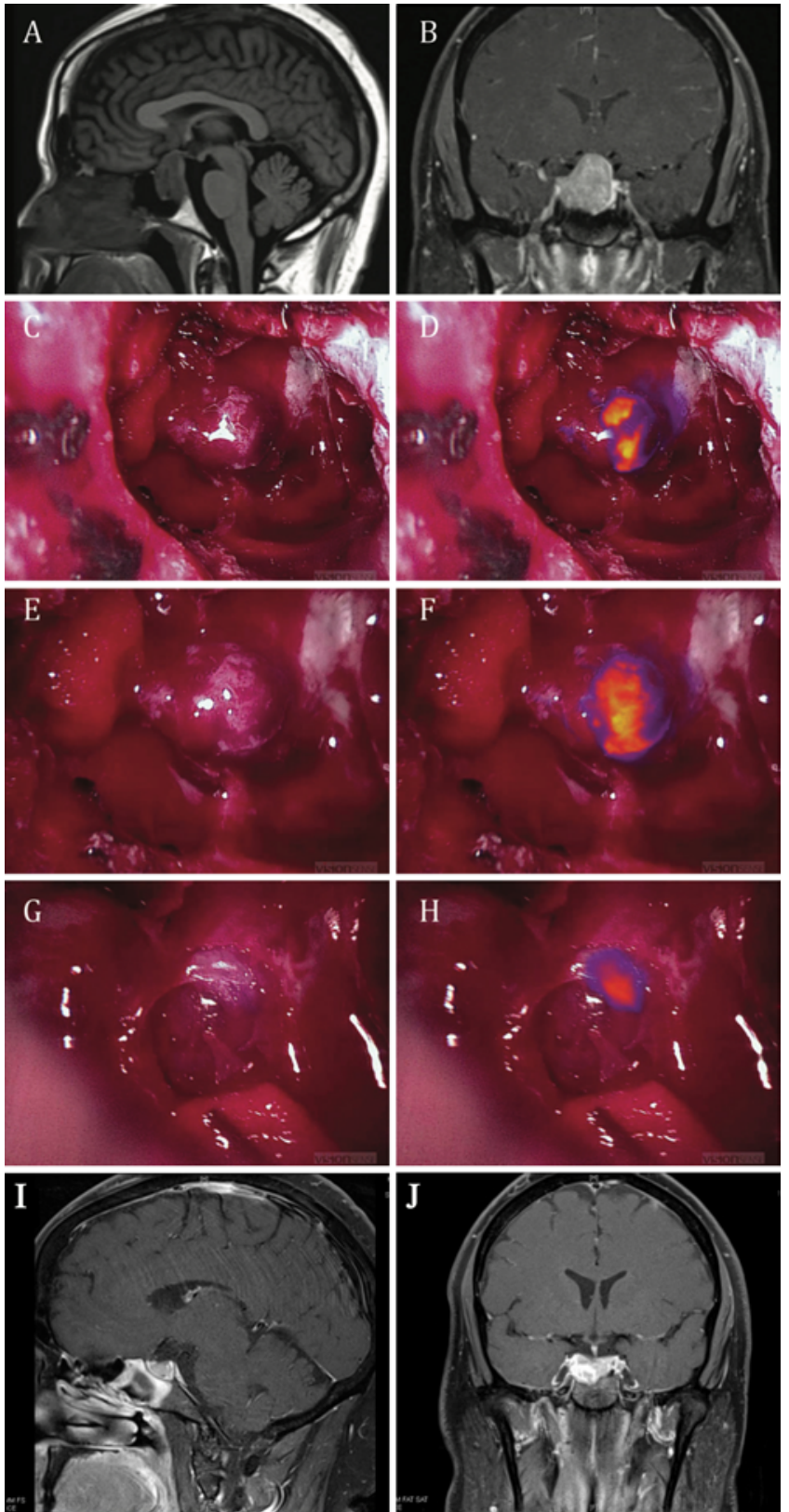

FIG. 5. Case 12. The FR $\alpha \mathrm{H}$-score of 270 demonstrates strong fluorescence, regardless of endoscope distance. A and B: Sagittal (A) and coronal (B) preoperative MR images demonstrating a sellar mass. $C$ and D: With MOCRs spanning approximately $30 \%$ of the field with white light (C), the tumor fluoresces with an SBR of 3.3 (D). E and F: With MOCRs spanning approximately $75 \%$ of the field with white light $(E)$, the tumor fluoresces with an SBR of $3.9(\mathrm{~F})$. G and $\mathrm{H}$ : Visible light does not show convincing residual fluorescence $(G)$, but NIR shows strong residual fluorescence in the left side of the sella $(\mathrm{H})$. I and J: One-month postoperative sagittal (I) and coronal (J) MR images demonstrate a residual $1-\mathrm{cm}$ hypoenhancing nodule in the left side of the sella

NF adenomas: the functional status of the adenoma alone did not explain the variability in SBR.

\section{Endoscope Distance}

The signal intensity of light varies by the square of the distance, and as such we hypothesized that the endoscope
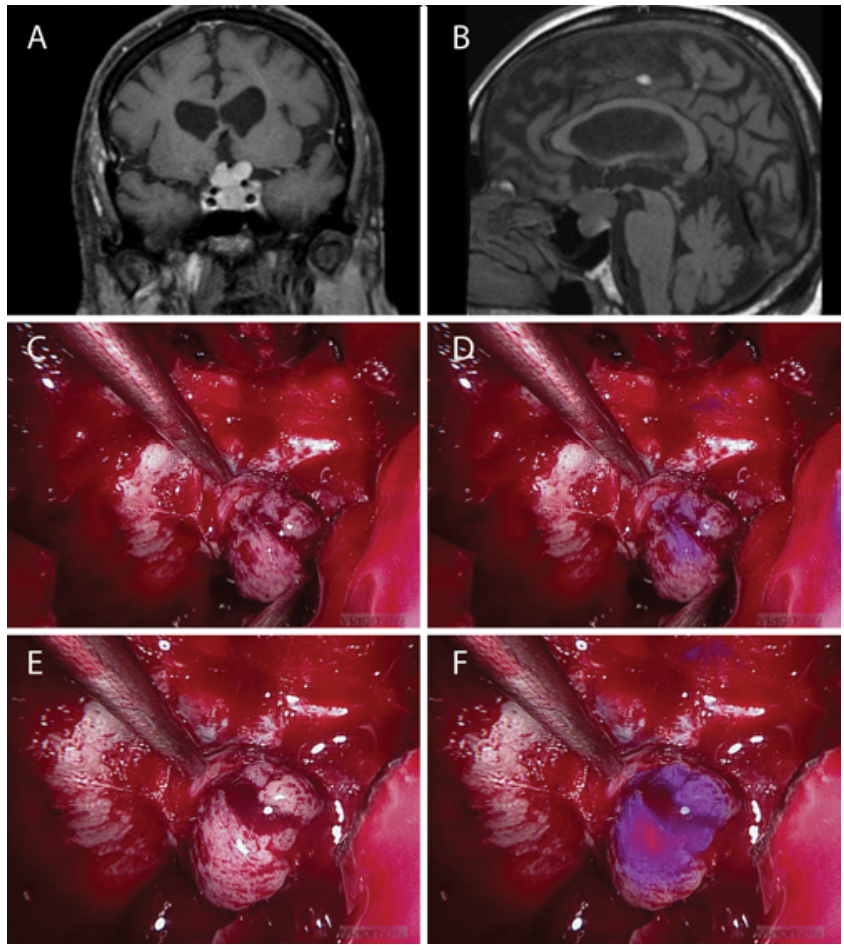

FIG. 6. Case 8. The FR $\alpha \mathrm{H}$-score of 5 demonstrates weak fluorescence that can be accentuated by moving the endoscope closer. A and B: Coronal (A) and sagittal (B) MR images demonstrating a sellar mass. C and D: With the MOCR spanning approximately $40 \%$ of the field with white light (C), the tumor fluoresces with an SBR of 1.1 (D). E and F: With the MOCR spanning approximately $70 \%$ of the field with white light $(\mathrm{E})$, the tumor fluoresces with an SBR of $2.1(\mathrm{~F})$.

distance to the sella may contribute to variability in SBR, especially within the tight confines of the nose and sella. In the absence of a reference standard, we measured the MOCR distance on the screen and divided it by the horizontal width of the video itself, which is captured as 720 line pairs in the horizontal dimension: MOCR ratio $=($ medial opticocarotid recess distance $) /$ (horizontal video capture distance).

The MOCR fraction ranged from 0.33 (which is onethird of the screen, implying that the endoscope is relatively far from the sella) to 1.0 (which means the MOCR is filling the entire sella). Indeed, the MOCR fraction can actually be $>1.0$ if the endoscope is introduced into the sella itself; however, we limited calculations of SBR to the more typical distances at which the sella is visualized.

MOCR was not a statistically significant univariate predictor of SBR in all patients (linear regression, $p=0.59$ ). However, multivariate analysis, which takes FR $\alpha$ expression into consideration in the linear regression model, did identify statistical significance. In both adenomas overexpressing FR $\alpha$ and adenomas that do not, the endoscope distance from the adenoma influenced SBR (Figs. 5-7).

\section{Time From Injection to Visualization}

Although the time required for OTL38 to saturate a tumor is proposed to be less than 30 minutes, its half-life in circulation is only approximately 25 minutes, suggesting that clearance of OTL38 from receptor-negative tissues 


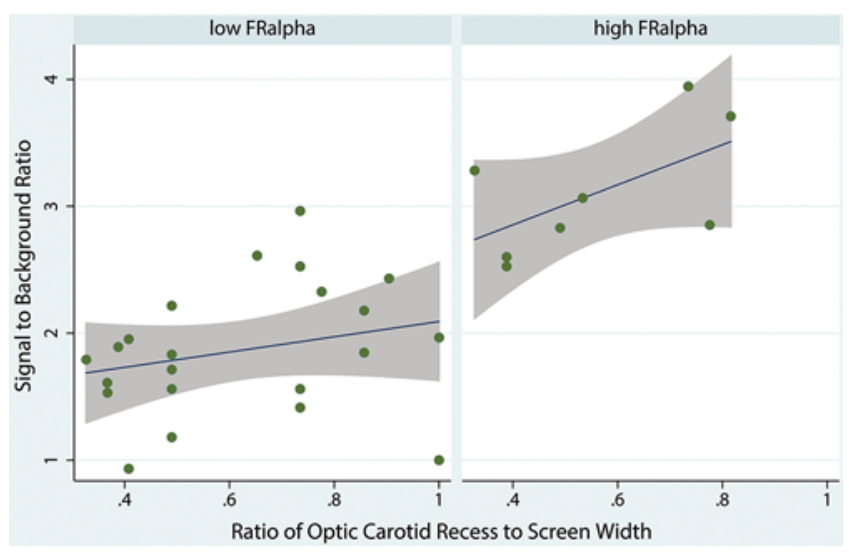

FIG. 7. SBR can be increased by simply moving the endoscope closer to the adenoma. This effect can lead to a low FR $\alpha$-expressing adenoma looking similar to a high FR $\alpha$ adenoma if careful attention is not paid. In both groups of adenomas, SBR increases as the distance between the endoscope and adenoma decreases (i.e., MOCR spans a greater percentage of the field). Figure is available in color online only.

should require 3-5 hours (i.e., 5 half-lives of OTL38 clearance should reduce the level of unbound imaging agent in circulation to $<5 \%$ of its initial level and the corresponding concentration of OTL38 in the tissues should soon follow). Because the fraction of OTL38 that is captured by a folate receptor will likely be internalized and retained by receptor-expressing cells, NF adenomas that express high levels of FR $\alpha$ should appear brightly fluorescent within approximately 30 minutes of injection and maintain their bright fluorescence for hours or even days.

In this study, the time from intravenous injection to initial surgical visualization of the adenoma ranged from 166 minutes to as long as 390 minutes, allowing sufficient time for most of the unbound OTL38 to clear from receptornegative tissues. For the 3 patients with FR $\alpha$ overexpression (regression $\mathrm{p}$ value $=0.28$ ) and 5 patients with NF adenomas (regression $\mathrm{p}$ value $=0.5$ ), we did not find a significant time dependence for SBR, which is consistent with the rapid uptake of OTL38 by FR $\alpha$-overexpressing cells.

However, in patients with low FR $\alpha$ expression, who should theoretically not demonstrate any significant NIR signal, we identified a linear trend toward higher SBR as time from injection increased ( $\mathrm{p}=0.0274$; Fig. 8). We discuss this issue in the limitations section in Discussion.

\section{NIR as a Predictor of Postoperative MRI Results}

All patients underwent postoperative MRI within 48 hours of surgery. Four of 15 patients showed residual neoplasm (Table 3). Excluding the patient in whom the laser malfunctioned in the middle of the procedure, 14 of 15 patients had intraoperative NIR images that were analyzed for fluorescence after excision of the main tumor. One patient demonstrated definite residual fluorescence and neoplasm on MRI, which was expected intraoperatively given the intracranial lateral extent of the neoplasm (Table 3 and Fig. 9). Her second-stage craniotomy performed 96 hours later demonstrated strong fluorescence even 4 days after injection, which is consistent with the anticipated internalization of the dye by the FR $\alpha$-overexpressing adenoma cells. Two of 3 patients with cavernous sinus involvement

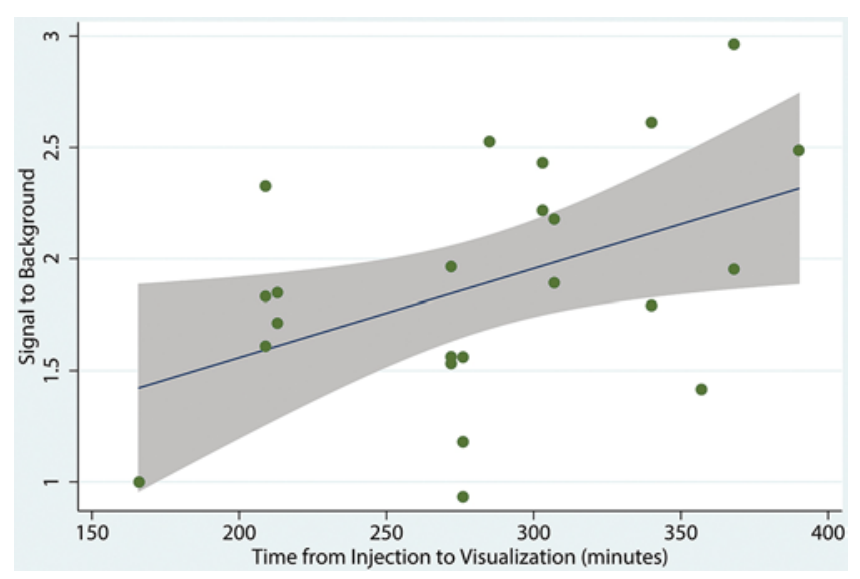

FIG. 8. The time from OTL38 injection to exposure and first imaging ranged from 166 to 372 minutes. The longer time period is correlated with increasing SBR in adenomas with low FR $\alpha$ expression $(p=0.0274)$. This suggests that there is an enhanced permeation and retention effect with the accumulation of dye in adenomas that do not overexpress FR $\alpha$. Figure is available in color online only.

seen on preoperative MRI exhibited residual neoplasm in the cavernous sinus or adjacent to the cavernous sinus on postoperative Day 1. In one of these patients (Case 12), the residual neoplasm was not seen using visible light alone, but a residual NIR signal was identified, thus predicting the findings on the follow-up MRI scan obtained 1 month later (Fig. 5).

For the 3 patients with high FR $\alpha$ expression, the postoperative MRI results correlated perfectly with the intraoperative imaging findings, and the residual fluorescence seen in 2 patients corresponded to the residual neoplasm seen on postoperative MRI (Table 3).

\section{Using NIR to Detect Margins}

On completion of standard adenoma resection, the Visionsense Iridium endoscope was introduced to inspect the margins of any potential residual adenoma. Excluding 4 patients from whom margin specimens were not taken, a total of 16 margin samples were collected from 11 patients. For all specimens, the true-positive rate was $86 \%$ and the true-negative rate was $89 \%$ using NIR, while the true-positive and true-negative rates were $80 \%$ and $89 \%$, respectively, using visible light. If we exclude functioning adenomas and only examine the 6 patients with NF adenomas, a total of 5 margin samples were collected; for both NIR and visible light, the true-positive rate was $100 \%$ and the true-negative rate was $100 \%$. Focusing on the 3 patients with FR $\alpha$ overexpression, a total of 3 margin samples were obtained. Two samples were positive for tumor, and these same 2 samples were also positive for fluorescence. One margin specimen was negative for fluorescence, and the final pathological analysis yielded only "fragments of crushed normal adenohypophysis." Hence, the sensitivity, specificity, positive predictive value, and negative predictive value were $100 \%$ for these 3 patients.

\section{Discussion}

Despite advancements in the surgical approach and visualization using endoscopic and microscopic transsphe- 

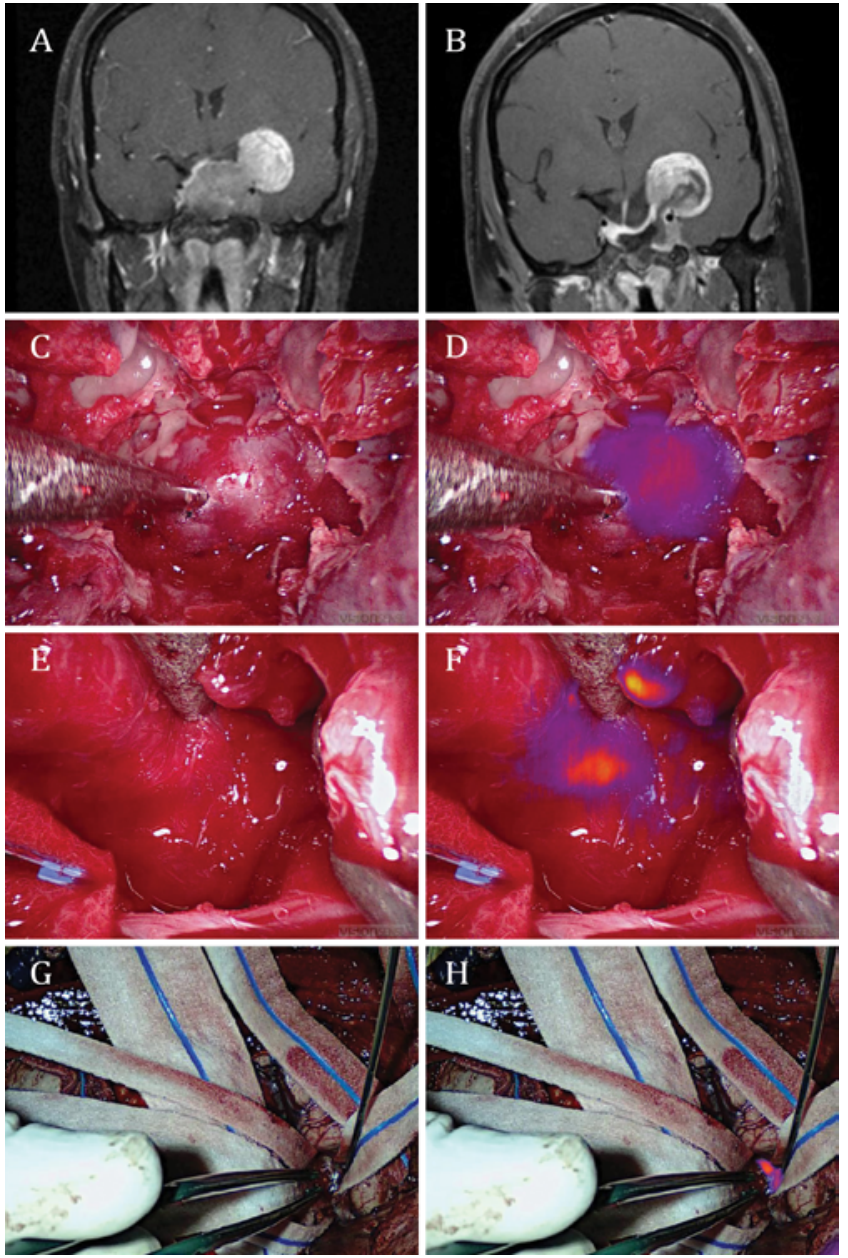

FIG. 9. Case 1. Comparison of MR images and intraoperative fluorescence of a pituitary adenoma before and after resection. A: Preoperative MR image showing a $25-\mathrm{mm}$ mass in the sella and a $28-\mathrm{mm}$ mass in the left middle cranial fossa. B: Postoperative MR image obtained after endoscopic surgery but before craniotomy, showing the incomplete resection of the sellar mass with cavernous sinus enhancement indicative of residual neoplasm. C and D: Preresection, intraoperative endoscopic images with NIR fluorescence off (C) and on (D), highlighting the sellar mass and surrounding bone and mucosa. E and F: Postresection, intraoperative endoscopic images with NIR fluorescence off $(E)$ and on $(F)$, showing residual fluorescence, especially to the patient's left side. $\mathbf{G}$ and $\mathrm{H}$ : Preresection craniotomy and intraoperative NIR imaging with NIR fluorescence off $(\mathrm{G})$ and on $(\mathrm{H})$ during the second surgery obtained 96 hours after OTL38 injection to remove the mass in the cranial fossa.

noidal techniques, GTR of pituitary adenomas remains a major surgical challenge. A recent published series documents a GTR rate of 50\%-70\%. ${ }^{16} \mathrm{~A}$ frequently studied intraoperative tool is MRI. Intraoperative MRI (iMRI) using a standard field (1.5-T MRI) has been shown to improve GTR rates. Berkmann et al. reported their experience with 109 patients, and demonstrated that after initial resection, GTR was seen in only $17 \% .{ }^{2}$ Using this iMRI information, the authors proceeded to resect more pituitary adenomas, thus raising the GTR rate from $17 \%$ to $49 \%$ in their cohort of patients. Intraoperative MRI thus promises the user the ability to improve GTR, but the same authors also noted that although iMRI showed residual tumor, residual pitu- itary adenomas decreased in volume by an average of $90 \%$ in half of these patients on follow-up imaging. ${ }^{1}$ Hence, iMRI may result in false positives, and a recent guideline statement from the Congress of Neurological Surgeons concludes that iMRI is not currently recommended. ${ }^{16}$ Consequently, adjunct imaging is still needed during pituitary adenoma resection to help achieve GTR.

Pioneering work performed by Evans et al. demonstrated that $\mathrm{FR} \alpha-\mathrm{a}$ membrane receptor that transports reduced folate-is overexpressed in NF pituitary adenoma cells. $^{7-9}$ Folate is an essential vitamin necessary for nucleic acid biosynthesis and is transported across the cell membrane in 3 ways: ubiquitously expressed reduced folate carrier, intestinal brush border-specific proton-coupled folate transporter, and folate receptor. ${ }^{27,39,40}$ Folate receptors exist in 4 forms - FR $\alpha, F R \beta, F R \gamma$, and FR $\delta$ - and FR $\alpha$ has been reported to be overexpressed in ovarian, lung, and breast carcinomas. ${ }^{3,20,33,35}$ In vivo SPECT imaging of folate receptor binding in healthy volunteers and patients has been performed using ${ }^{99 \mathrm{~m}} \mathrm{Tc}$-labeled etarfolatide, a folate-targeted technetium chelating agent, to demonstrate that folate receptors can be targeted for visualization. . $^{32,37}$

The ability to conjugate a folate molecule to a fluorescent contrast agent has been previously proposed to identify tumor nodules. Specifically, van Dam et al. published the first trial in humans that demonstrated intraoperative optical contrast during surgery for ovarian cancer using a folate-fluorescein (EC17) conjugate to detect intraoperative metastasis. ${ }^{36}$ Subsequently, Hoogstins et al. studied the use of OTL38 in ovarian carcinomas, which overexpress FR $\alpha .{ }^{14}$ Based on these preliminary findings, we hypothesized that FR $\alpha$ overexpression in pituitary adenomas may provide a window of opportunity for neurosurgeons to visualize pituitary adenomas during surgery. Ultimately, we propose that this technology may be able to improve the GTR of pituitary adenomas.

\section{NIR Visualization}

In this study, we investigated the potential of using intraoperative, fluorescent, folate receptor targeting to improve the GTR of pituitary adenoma. For several reasons, we chose to use OTL38 (the NIR fluorescent, folateconjugated dye) over EC17 (the visible light, fluorescent, folate-conjugated dye as used in the ovarian cancer trial published by van Dam et al. ${ }^{36}$ ). First, there is minimal autofluorescence in the NIR spectrum in CNS tissues. In addition, NIR has a longer wavelength, which can potentially provide a benefit because NIR light can penetrate the normal dura. In our prior work using Second Window ICG, where we deliver an extremely high dose of ICG intravenously and then wait 24 hours before surgical visualization, we have been able to demonstrate the NIR signal through normal dura and normal brain parenchyma. ${ }^{23} \mathrm{An}-$ other benefit of NIR is that our group has extensive experience using NIR fluorescence to study gliomas and meningiomas. ${ }^{22,23}$ One of the main challenges of working in the NIR spectrum is that humans cannot see light in the NIR spectrum. Indeed, most neurosurgeons have experience using NIR during vascular neurosurgery (for example, aneurysm clipping), and the image is only seen on the screen in black and white. In contrast, we chose to employ the Vi- 


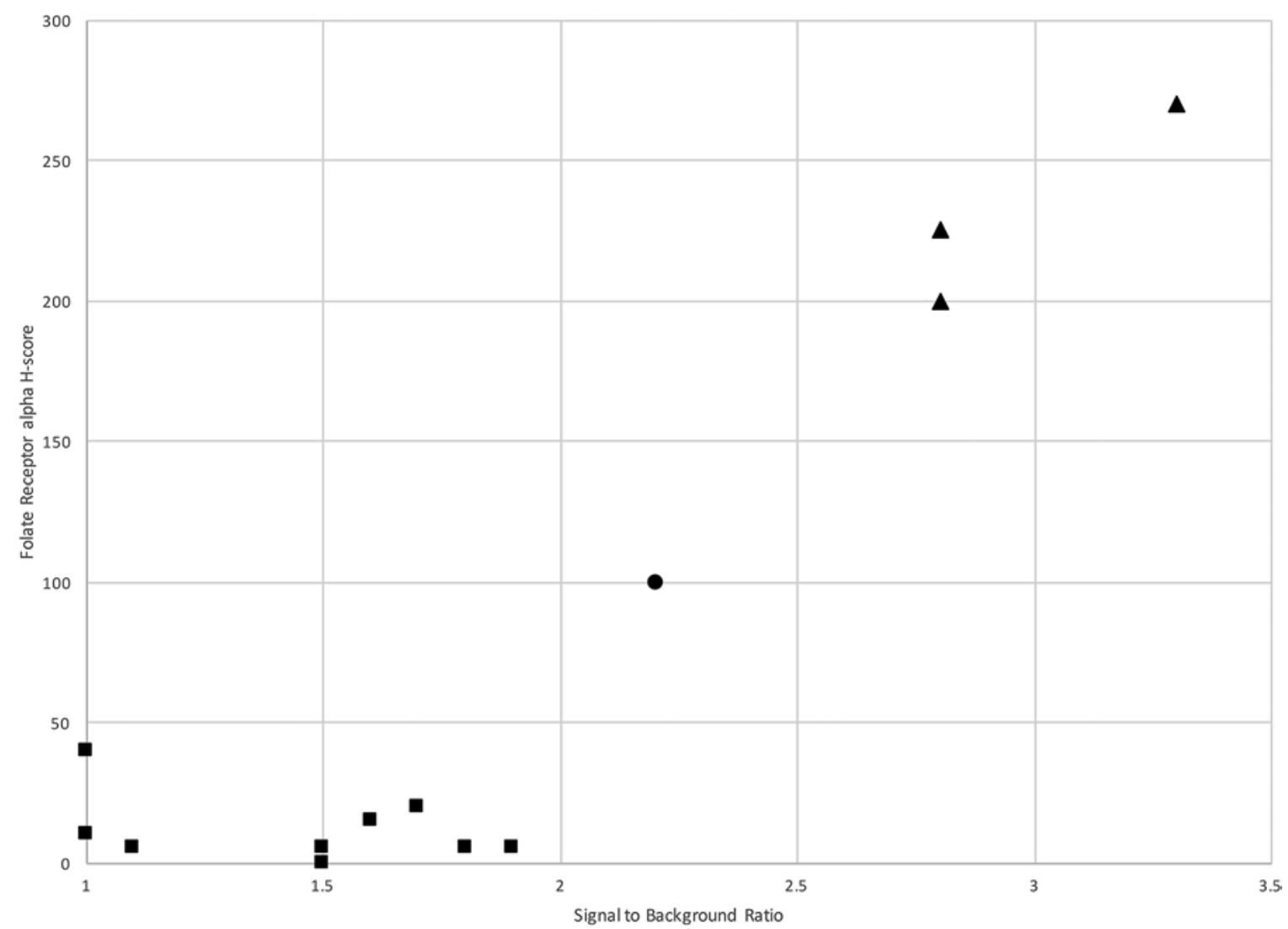

FIG. 10. SBR, as measured intraoperatively after exposing the adenoma through dura, is a strong predictor of FR $\alpha$ expression levels on pathological analysis. The adenomas that overexpress FR $\alpha$ (black triangles) and adenomas that do not (black rectangles) are easily distinguishable on intraoperative SBR, while 1 adenoma with SBR in the intermediate range (black circle) turned out to have intermediate FR $\alpha$ expression. Here, SBRs were measured with the MOCRs spanning $30 \%-50 \%$ of the screen.

sionsense Iridium system, which simultaneously provides the real-time overlay of visible light and NIR as a "pseudocolor" map of the NIR signal superimposed on the visible light view (Figs. 1 and 2). This allowed the surgeon to work with the endoscope in visible light and then turn on NIR when necessary. The Visionsense Iridium system has been shown to have high sensitivity and a wide dynamic range, making it very suitable for our purposes. ${ }^{5}$

\section{FR $\alpha$ as a Target for Optical Contrast}

In this study, 3 of 6 patients (50\%) with NF adenomas demonstrated FR $\alpha$ overexpression based on the immunohistochemical analysis of the paraffin-embedded specimens. The NIR SBR of the 12 adenomas with low FR $\alpha$ was $1.6 \pm 0.43$, and the SBR of the 3 adenomas with high FR $\alpha$ was $3.0 \pm 0.27$ ( $\mathrm{p}<0.01$, t-test). Thus, by keeping the endoscope farther from the sella (MOCR $<50 \%$ of video screen) and using an SBR cutoff value of 2.5, we could perfectly predict FR $\alpha$ expression in all patients with an area under the receiver operating characteristic curve of 1.0 (Fig. 10). This could be used to predict adenomas that intraoperatively overexpress FR $\alpha$.

An important finding of this pilot study is that the endoscope distance and injection-to-visualization time are critical. SBR can be artificially increased by simply bringing the endoscope closer to the tumor. Figure 7 demonstrates that SBR increased in all tumors as the endoscope moved closer to the tumor. We have found that maintaining an endoscope distance that is farther from the sella (where the MOCR spans less than half of the video screen) leads to the best ability to differentiate high and low SBR, which correspond to high and low FR $\alpha$ expression, respectively. There is obvious patient variability with respect to the distance between the right and left MOCRs, as reported by Nunes et al. (the average MOCR distance was $11 \pm 1$ $\mathrm{mm}) .^{29}$ Nevertheless, in the absence of a laser range finder to provide the absolute distance, we used this internal landmark as a proxy for distance.

\section{Clinical Benefit}

GTR of an NF pituitary adenoma is often limited by intrinsic factors such as the circumferential invasion of the cavernous sinus (Knosp Grade 4 invasion). ${ }^{31}$ Berkmann et al. demonstrated that cytoreduction could be improved in the iMRI suite by taking the time to obtain an MRI scan and then performing further resection. ${ }^{2}$ Similarly, realtime intraoperative molecular imaging with an optical contrast agent such as folate-NIR dye may be able to replicate the iMRI findings in the subset of pituitary adenomas that overexpress FR $\alpha$. We believe that intraoperative, folate receptor-targeted, fluorescent tumor imaging may provide important intraoperative information that influences surgical decision making and allows the surgeon to improve resection. In this limited series of 3 patients with 
high FR $\alpha$ overexpression, the intraoperative fluorescence perfectly predicted the postoperative MRI findings. In 1 patient (Case 7), no residual fluorescence was seen intraoperatively, and no residual tumor was seen on postoperative MRI (Fig. 2). In 2 patients (Cases 1 and 12), intraoperative fluorescence demonstrated a residual adenoma to the left of the sella, and in both cases MRI demonstrated residual adenoma on the left side (Figs. 5 and 10). This suggests a strong correlation between intraoperative fluorescent imaging and postoperative MRI.

With respect to margin detection, we believe that this technique has excellent sensitivity and specificity for patients with high FR $\alpha$ expression. In a margin analysis of 3 patients with high FR $\alpha$ expression, OTL38 showed major clinical value. Three biopsy specimens were obtained from 2 of the patients. There was a perfect correlation between intraoperative NIR fluorescence and the pathological analysis, demonstrating $100 \%$ sensitivity, specificity, positive predictive value, and negative predictive value. We recognize, of course, that these results must be extended to a larger population of patients with NF pituitary adenoma.

\section{Limitations}

A shortcoming of our study was the small number of patients who had FR $\alpha$-overexpressing adenomas. Evans et al. concluded that all $11 \mathrm{NF}$ adenomas demonstrated positive FR $\alpha$ overexpression on immunohistochemical analysis, and none of 7 functioning adenomas demonstrated this overexpression.? In our study, none of 9 functioning adenomas demonstrated FR $\alpha$ overexpression, and only 3 of $6(50 \%)$ of the NF adenomas demonstrated FR $\alpha$ overexpression. Because of this low FR overexpression, we primarily focused this pilot study on predicting FR $\alpha$ overexpression using pathological immunohistochemical analysis as the gold standard. Without the proper identification of those tumors with high FR $\alpha$ overexpression, this technique could result in significant false-negative results. We will continue to expand this work in nonfunctioning adenomas, but there may also be a role for predicting which patients will benefit from this dye before surgery. Preoperative radionuclide imaging with ${ }^{99 \mathrm{~m} T c}$ EC20 could be a viable option. ${ }^{19,32,37}$

Another limitation of this study is that we were only able to analyze 5 margin specimens of adenomas with an FR $\alpha \mathrm{H}$-score $>100$ in order to compare visual and tactile discrimination of the tumor to OTL38 fluorescence, which showed that both approaches correctly discriminate neoplasms from normal tissue with $100 \%$ sensitivity and specificity. Future studies with larger sample sizes will further examine the validity of using OTL38 for margin discrimination.

A third limitation of the study is the possibility of false positives when using the NIR signal. Many pituitary adenomas in this study did not overexpress FR $\alpha$ and thus should not have demonstrated any significant NIR signal. Nevertheless, we believe that there may be a small accumulation of OTL38, even in the pituitary adenomas as shown in Figs. 6 and 8. This observation likely derives from the fact that the tumor vasculature of a pituitary adenoma is generally leakier than healthy tissue vasculature, leading to an enhanced permeation and retention effect in the tumor that allows some contrast agents to passively accumulate in the tumor tissue more effectively than in normal tissues. ${ }^{26}$ Because the magnitude of this effect is small, especially with low-molecular-weight contrast agents such as OTL38, significant contrast cannot be seen until the agent is cleared from normal tissues. Moreover, because the contrast agent is not receptor bound, it will wash out of the tumor over time. We suspect that adenomas with little or no FR $\alpha$ expression show increased SBR as time passes because the normal tissues clear OTL38 faster than the tumor. Thus, if OTL38's injection-to-visualization time exceeds 5-6 hours, adenomas with low FR $\alpha$ expression may demonstrate high SBR, leading to false-positive findings.

Another consideration is that there are other folate receptor variants, such as FR $\beta$, that are expressed on activated, but not quiescent, macrophages. We did not stain for FR $\beta$ in this study because we did not see macrophage accumulation in the slide blocks. Nevertheless, this is a potential source of OTL38 uptake that would result in fluorescence.

A final issue that needs to be considered is that there is a learning curve to intraoperatively performing video analysis of the NIR signal using the Visionsense Iridium 4-mm endoscope. Although the endoscope has a flat field of illumination in the visible light spectrum, the NIR excitation light source is brighter in the center than in the periphery. Thus, background points must be taken closer to the tumor rather than at the peripheries of the field. In addition, in the absence of a laser range finder to measure distance, approximating MOCR and screen size is not always easy if the surgeon has not opened the sphenoid sinus wide enough to visualize these anatomical structures.

\section{Conclusions}

In this paper, we present the first clinical study utilizing a folate receptor-targeted fluorescent dye for resection of pituitary adenomas. Administering the intravenous folate dye, OTL38, safely provided the optical contrast that allowed the discrimination of high and low FR $\alpha$ expression. We confirmed the findings of previous studies that reported only NF pituitary adenomas overexpress FR $\alpha$. By just focusing on the 3 patients with confirmed FR $\alpha$ overexpression, OTL38 was able to predict postoperative MRI findings and provide $100 \%$ sensitivity and specificity of the margins. Although these results are encouraging, we consider this paper to represent an early-stage innovation. In our future work, we will focus only on NF adenomas in which this modality is the most likely to be clinically relevant. In addition, we will continue to refine the imaging technique and analysis as distance appears to be a critical factor.

\section{Acknowledgments}

This study was supported in part by the National Institutes of Health (grant no. R01 CA193556 awarded to S.S.) and the Institute for Translational Medicine and Therapeutics of the Perelman School of Medicine at the University of Pennsylvania (awarded to J.Y.K.L.). In addition, the research reported in this publication was supported by the National Center for Advancing Translational Sciences of the National Institutes of Health (award no. UL1TR000003 
awarded to J.Y.K.L.). The content is solely the responsibility of the authors and does not necessarily represent the official views of the NIH.

\section{References}

1. Berkmann S, Schlaffer S, Buchfelder M: Tumor shrinkage after transsphenoidal surgery for nonfunctioning pituitary adenoma. J Neurosurg 119:1447-1452, 2013

2. Berkmann S, Schlaffer S, Nimsky C, Fahlbusch R, Buchfelder M: Intraoperative high-field MRI for transsphenoidal reoperations of nonfunctioning pituitary adenoma. J Neurosurg 121:1166-1175, 2014

3. Boogerd LSF, Boonstra MC, Beck AJ, Charehbili A, Hoogstins CES, Prevoo HAJM, et al: Concordance of folate receptor- $\alpha$ expression between biopsy, primary tumor and metastasis in breast cancer and lung cancer patients. Oncotarget 7:17442-17454, 2016

4. Budwit-Novotny DA, McCarty KS, Cox EB, Soper JT, Mutch DG, Creasman WT, et al: Immunohistochemical analyses of estrogen receptor in endometrial adenocarcinoma using a monoclonal antibody. Cancer Res 46:5419-5425, 1986

5. DSouza AV, Lin H, Henderson ER, Samkoe KS, Pogue BW: Review of fluorescence guided surgery systems: identification of key performance capabilities beyond indocyanine green imaging. J Biomed Opt 21:80901, 2016

6. Elhadi AM, Hardesty DA, Zaidi HA, Kalani MYS, Nakaji $\mathrm{P}$, White WL, et al: Evaluation of surgical freedom for microscopic and endoscopic transsphenoidal approaches to the sella. Neurosurgery 11 (Suppl 2):69-79, 2015

7. Evans CO, Reddy P, Brat DJ, O'Neill EB, Craige B, Stevens VL, et al: Differential expression of folate receptor in pituitary adenomas. Cancer Res 63:4218-4224, 2003

8. Evans CO, Yao C, Laborde D, Oyesiku NM: Folate receptor expression in pituitary adenomas cellular and molecular analysis. Vitam Horm 79:235-266, 2008

9. Evans CO, Young AN, Brown MR, Brat DJ, Parks JS, Neish AS, et al: Novel patterns of gene expression in pituitary adenomas identified by complementary deoxyribonucleic acid microarrays and quantitative reverse transcription-polymerase chain reaction. J Clin Endocrinol Metab 86:30973107,2001

10. Ezzat S, Asa SL, Couldwell WT, Barr CE, Dodge WE, Vance ML, et al: The prevalence of pituitary adenomas: a systematic review. Cancer 101:613-619, 2004

11. Faje A, Tritos NA, Swearingen B, Klibanski A: Neuroendocrine disorders: pituitary imaging. Handb Clin Neurol 136: $873-885,2016$

12. Galt JR, Halkar RK, Evans CO, Osman NA, LaBorde D, Fox $\mathrm{TH}$, et al: In vivo assay of folate receptors in nonfunctional pituitary adenomas with ${ }^{99 \mathrm{~m} T c-\text { folate SPECT/CT. J Nucl Med }}$ 51:1716-1723, 2010

13. Greenman Y, Cooper O, Yaish I, Robenshtok E, Sagiv N, Jonas-Kimchi T, et al: Treatment of clinically nonfunctioning pituitary adenomas with dopamine agonists. Eur J Endocrinol 175: 63-72, 2016

14. Hoogstins CES, Tummers QRJG, Gaarenstroom KN, de Kroon CD, Trimbos JBMZ, Bosse T, et al: A novel tumorspecific agent for intraoperative near-infrared fluorescence imaging: A translational study in healthy volunteers and patients with ovarian cancer. Clin Cancer Res 22:2929-2938, 2016

15. Kikuchi R, Toda M, Wakahara S, Fujiwara H, Jinzaki M, Yoshida K: Analysis of the medial opticocarotid recess in patients with pituitary macroadenoma using three-dimensional images. World Neurosurg 93:139-143, 2016

16. Kuo JS, Barkhoudarian G, Farrell CJ, Bodach ME, Tumialan LM, Oyesiku NM, et al: Congress of Neurological Surgeons systematic review and evidence-based guideline on surgical techniques and technologies for the management of patients with nonfunctioning pituitary adenomas. Neurosurgery 79:E536-E538, 2016

17. Labib MA, Prevedello DM, Fernandez-Miranda JC, Sivakanthan S, Benet A, Morera V, et al: The medial opticocarotid recess: an anatomic study of an endoscopic "key landmark" for the ventral cranial base. Oper Neurosurg 72 (1 Suppl Operative):66-76, 2013

18. Larysz D, Żebracka-Gala J, Rudnik A, Hasse-Lazar K, Kowalska M, Jarząb M, et al: Expression of genes FOLR1, BAG1 and LAPTM4B in functioning and non-functioning pituitary adenomas. Folia Neuropathol 50:277-286, 2012

19. Leamon CP, Parker MA, Vlahov IR, Xu LC, Reddy JA, Vetzel M, et al: Synthesis and biological evaluation of EC20: a new folate-derived, ${ }^{99 \mathrm{~m} T c}$-based radiopharmaceutical. Bioconjug Chem 13:1200-1210, 2002

20. Ledermann JA, Canevari S, Thigpen T: Targeting the folate receptor: diagnostic and therapeutic approaches to personalize cancer treatments. Ann Oncol 26:2034-2043, 2015

21. Lee JYK, Bohman LE, Bergsneider M: Contemporary neurosurgical techniques for pituitary tumor resection. J Neurooncol 117:437-444, 2014

22. Lee JYK, Pierce JT, Thawani JP, Zeh R, Nie S, MartinezLage M, et al: Near-infrared fluorescent image-guided surgery for intracranial meningioma. J Neurosurg [epub ahead of print April 7, 2017. DOI: 10.3171/2016.10.JNS16636]

23. Lee JYK, Thawani JP, Pierce J, Zeh R, Martinez-Lage M, Chanin M, et al: Intraoperative near-infrared optical imaging can localize gadolinium-enhancing gliomas during surgery. Neurosurgery 79:856-871, 2016

24. Losa M, Mortini P, Barzaghi R, Ribotto P, Terreni MR, Marzoli SB, et al: Early results of surgery in patients with nonfunctioning pituitary adenoma and analysis of the risk of tumor recurrence. J Neurosurg 108:525-532, 2008

25. Madajewski B, Judy BF, Mouchli A, Kapoor V, Holt D, Wang $\mathrm{MD}$, et al: Intraoperative near-infrared imaging of surgical wounds after tumor resections can detect residual disease. Clin Cancer Res 18:5741-5751, 2012

26. Maeda H, Wu J, Sawa T, Matsumura Y, Hori K: Tumor vascular permeability and the EPR effect in macromolecular therapeutics: a review. J Control Release 65:271-284, 2000

27. Matherly LH, Goldman DI: Membrane transport of folates. Vitam Horm 66:403-456, 2003

28. McCarty KS Jr, Szabo E, Flowers JL, Cox EB, Leight GS, Miller L, et al: Use of a monoclonal anti-estrogen receptor antibody in the immunohistochemical evaluation of human tumors. Cancer Res 46 (8 Suppl):4244s-4248s, 1986

29. Nunes CF, Prevedello DMS, Carrau RL, da Fonseca COP, Landeiro JA: Morphometric analysis of the medial opticocarotid recess and its anatomical relations relevant to the transsphenoidal endoscopic endonasal approaches. Acta Neurochir (Wien) 158:319-324, 2016

30. O'Malley BW Jr, Grady MS, Gabel BC, Cohen MA, Heuer GG, Pisapia J, et al: Comparison of endoscopic and microscopic removal of pituitary adenomas: single-surgeon experience and the learning curve. Neurosurg Focus 25(6):E10, 2008

31. Paluzzi A, Fernandez-Miranda JC, Tonya Stefko S, Challinor S, Snyderman CH, Gardner PA: Endoscopic endonasal approach for pituitary adenomas: a series of 555 patients. Pituitary 17:307-319, 2014

32. Sega EI, Low PS: Tumor detection using folate receptor-targeted imaging agents. Cancer Metastasis Rev 27:655-664, 2008

33. Shi H, Guo J, Li C, Wang Z: A current review of folate receptor alpha as a potential tumor target in non-small-cell lung cancer. Drug Des Devel Ther 9:4989-4996, 2015

34. Thawani JP, Ramayya AG, Pisapia JM, Abdullah KG, Lee JY, Grady MS: Operative strategies to minimize complica- 
tions following resection of pituitary macroadenomas. J Neurol Surg Part B Skull Base 78:184-190, 2017

35. Toffoli G, Cernigoi C, Russo A, Gallo A, Bagnoli M, Boiocchi M: Overexpression of folate binding protein in ovarian cancers. Int J Cancer 74:193-198, 1997

36. van Dam GM, Themelis G, Crane LM, Harlaar NJ, Pleijhuis RG, Kelder W, et al: Intraoperative tumor-specific fluorescence imaging in ovarian cancer by folate receptor- $\alpha$ targeting: first in-human results. Nat Med 17:1315-1319, 2011

37. Yamada Y, Nakatani H, Yanaihara H, Omote M: Phase I clinical trial of ${ }^{99 \mathrm{~m} T c}$-etarfolatide, an imaging agent for folate receptor in healthy Japanese adults. Ann Nucl Med 29:792798, 2015

38. Yang Y, Zhan G, Liao J, Dang R, Wang H, Li Y, et al: Morphological characteristics of the sphenoid sinus and endoscopic localization of the cavernous sinus. J Craniofac Surg 26:1983-1987, 2015

39. Zhao R, Diop-Bove N, Visentin M, Goldman ID: Mechanisms of membrane transport of folates into cells and across epithelia. Annu Rev Nutr 31:177-201, 2011

40. Zhao R, Goldman ID: The proton-coupled folate transporter: physiological and pharmacological roles. Curr Opin Pharmacol 13:875-880, 2013

\section{Disclosures}

The authors report the following. Dr. Lee owns stock options in Visionsense. Dr. Low has direct stock ownership in On Target Laboratories. Dr. Singhal holds patent rights over the technologies presented in this article.

\section{Author Contributions}

Conception and design: Lee, Grady. Acquisition of data: Lee, Cho, Zeh, Pierce, Martinez-Lage, Grady. Analysis and interpretation of data: Cho. Drafting the article: Cho. Critically revising the article: Lee, Adappa, Palmer, Newman, Learned, White, Kharlip, Snyder, Low, Singhal, Grady. Statistical analysis: Lee, Cho. Administrative/technical/material support: Lee, Low. Study supervision: Lee.

\section{Correspondence}

John Y. K. Lee, University of Pennsylvania, 235 S Eighth St., Philadelphia, PA 19106. email: leejohn@uphs.upenn.edu. 